Revista de la red interuniversitaria de estudios sobre las literaturas rioplatenses contemporáneas en Francia

$18 \mid 2018$

El río y la ciudad

\title{
Los poetas no saben (casi) nada del río
}

\section{Edgardo Dobry}

\section{OpenEdition}

\section{Journals}

Edición electrónica

URL: http://journals.openedition.org/lirico/5635

DOI: $10.4000 /$ lirico.5635

ISSN: 2262-8339

Editor

Réseau interuniversitaire d'étude des littératures contemporaines du Río de la Plata

Referencia electrónica

Edgardo Dobry, «Los poetas no saben (casi) nada del río », Cuadernos LIRICO [En línea], 18 | 2018,

Puesto en línea el 12 octubre 2018, consultado el 21 abril 2019. URL : http://journals.openedition.org/ lirico/5635 ; DOl : 10.4000/lirico.5635

Este documento fue generado automáticamente el 21 abril 2019.

\section{(c) (i) (9)}

Cuadernos LIRICO está distribuido bajo una Licencia Creative Commons Atribución-NoComercialSinDerivar 4.0 Internacional. 


\title{
Los poetas no saben (casi) nada del río
}

\author{
Edgardo Dobry
}

En la poesía clásica el río es una alegoría o un arquetipo. Es el río de "nuestras vidas" que "van a dar a la mar": tiempo frente a eternidad. O quizás: tiempo que corre frente a tiempo muerto. En el soneto de Quevedo "A Roma sepultada en ruinas", el Tíber simboliza lo que siempre fluye y es siempre igual, frente a los monumentos que el hombre construyó con vana aspiración de persistencia: "Huyó lo que era firme y solamente/ lo fugitivo permanece y dura". Por eso, "Buscas a Roma en Roma, oh peregrino,/ y a Roma misma en Roma no la hallas...". El tiempo divide la ciudad ideal de la ciudad real, y por eso el poema explora el campo de una anti-metáfora: en lugar de haber dos nombres para el mismo objeto hay uno solo para dos cosas distintas, aunque ocupen el mismo espacio y se llamen igual. Hay una Roma buscada y otra encontrada; la Roma imperial, o lo que queda de ella, y la Roma actual. Si, como sentencia Aristóteles en la Poética, la historia trata de lo particular y la poesía de lo universal, en el soneto de Quevedo están presentes las dos Romas, histórica y poética. ¿Cuál es la poética, la que se busca o la que se encuentra? ¿O lo poético, en tanto universal, sería la constatación de que "huyó lo que era firme y solamente/ lo fugitivo permanece y dura"? Considerando que el soneto, de mediados del siglo XVII, es versión de otro escrito por Joaquim du Bellay unos cien años antes (“Nouveau venu, qui cherches Rome en Rome/ Et rien de Rome en Rome n'aperçois..."), la complejidad de original irrecuperable y copia presente se acrecienta. La Roma que el peregrino encuentra es solo una (mala) traducción de la que busca. Solo el río que, al atravesar la ciudad europea, separa el espacio urbano en dos, atestigua que aquella y esta ciudad son dos momentos de un devenir. Puede llamarse "Rive Gauche" o "South Bank" o "Buda": toda ciudad atravesada por un río es una entidad dividida en dos. La ciudad se transforma, los barrios ganan y pierden prestigio, las capas de la historia son múltiples; solo aquello natural entre lo artificioso -el río- recuerda que origen y momento actual son indivisibles, incluso cuando el vínculo entre ambos parece borrado. El río es la única garantía de conjunción entre lo que "era firme" y "lo fugitivo". Un contraste parecido irrumpe en un verso de W. H. Auden: "The peasant river was untempted by the fashionable quays" [No tentaban al río campesino los muelles elegantes] ${ }^{1}$; lo natural del 
río revela lo artificioso de la ciudad y de la vida urbana. Pero lo fugitivo, en el río de Quevedo y en el de Auden, no es lo arcaico sino lo que está fuera del tiempo, precisamente porque encarna al tiempo: lo que nunca deja de fluir.

En otro soneto de Quevedo, uno de los más célebres de la lengua, la "llama" del alma sabe "nadar el agua fría": atravesar a la vez el Aqueronte y el Leteo, sin beber el agua del olvido; así las cenizas podrán ser "polvo enamorado". Juan Gelman intervino estos versos en una de sus Notas de 1979: "cruza mi alma la agua fría donde/ flotan los rostros de los compañeros"2. Acerca de esto escribió Geneviève Fabry: "La llama se transforma en el poema de Gelman en alma, mientras que la evocación del río pierde sus connotaciones mitológicas para adquirir otras, más inquietantes. Quizás ya supiera Gelman en aquel entonces que los cuerpos torturados y asesinados por lo esbirros de la Junta militar argentina eran arrojados desde helicópteros al Río de la Plata donde el agua fría ofrecería una sepultura privada de todo rito funerario"'.

3 En el soneto de Góngora: "Cuantas al Duero le he negado ausente/ tantas al Betis lágrimas le fío", los ríos son metonimia de las ciudades de Valladolid y Sevilla; y además ambos son un "Erídano segundo". Es decir, una imagen del río mítico donde Faetón se ahogó por no saber manejar el carro del Sol; un poco más allá, "arde el mar", en una de esas simetrías sonoras (la partícula "ar", en este caso) que parecen el elemento engendrador de la imaginación musical gongorina; igualmente, al final, "humea el mundo". La caída al río de Faetón consuma el choque momentáneo del mito y el mundo, lo resuelve en un chapoteo (splash), como el de Ícaro en el cuadro de Brueghel y en el poema de Auden "Musée des Beaux Arts", que lo describe: "the ploughman may/ Have heard the splash" (el campesino/ habrá oído el chapoteo). Solo un chapoteo indica el punto y el momento en el que mundo celeste y mundo terrestre colisionan, de modo semejante a cómo el agua fluyente del Tíber indica la fugitiva permanencia de una Roma en la otra Roma.

El siglo XX no rompió del todo con las identificaciones convencionales entre río y tiempo. Borges, por ejemplo, adhiere de lleno a ese tópico de ríos abstractos cuando escribe al principio de un poema de $E l$ hacedor, singularmente titulado "Arte poética":

Mirar el río hecho de tiempo y agua

y recordar que el tiempo es otro río,

saber que nos perdemos como el río

y que los rostros pasan como el agua ${ }^{4}$.

5 Los "rostros" que ve Borges en el agua, ¿serán (involuntariamente) premonitorios de los que verá Gelman veinte años más tarde? En una reseña de Espantapájaros de Girondo, publicada en Martín Fierro ( $\mathrm{n}^{\circ}$ 18, 1926), Borges insinuaba ya que el procedimiento de la metáfora inesperada, consustancial a la vanguardia, era en verdad tan antiguo como la poesía misma. Para ello, citaba a Virgilio: pontem indignatus Araxes: el orgulloso río Aras, en el Asia Menor, se indigna contra el puente que pretende surcarlo y arremete contra él. El río es prosopopeya del orgullo ciego, y el puente, arruinado por el ímpetu del agua, ocupa una posición semejante a la de "aquello que era firme" en el soneto de Quevedo.

Desde hace siglos, entonces, los poetas miran los ríos pero no ven en verdad el río: ven una alegoría del tiempo o de lo intemporal, o de lo intemporal del tiempo que divide y a la vez une origen y devenir. Por eso aprender algo acerca del río -de un río particular y no del río universal, según la discriminación aristotélica- parece extremadamente difícil. Quizás, también, porque las capas de metáforas fosilizadas sobre el agua se interponen entre la mirada y su objeto. Algunos poetas prefieren desafiarse a decir algo sobre el agua corriente, como Francis Ponge -“el agua está loca a causa de esta necesidad histérica de 
no obedecer más que a su peso, que la posee como una idea fija"5-, o quieta en un vaso, como José Gorostiza: "No obstante -oh paradoja- constreñida/ por el rigor del vaso que la aclara,/ el agua toma forma"6. En cuanto a los ríos, se puede por supuesto obtener datos técnicos, muy importantes por otra parte, sobre todo en el continente americano, donde son vías de comunicación de primer orden y donde recorren distancias enormes y se desaguan en deltas extensísimos. Al principio de El río sin orillas, Juan José Saer dejó constancia del orgullo local que tales récords pueden sustentar. En el vuelo que lo lleva de París a Buenos Aires para cumplir con el encargo que es el germen de ese libro, Saer cuenta que se encuentra con un conocido, a quien le confiesa el objeto de su viaje: "Me espetó, con un tono de advertencia amenazadora: '¿Sabías que la superficie del Río de la Plata (34.000 kilómetros cuadrados) es equivalente a la de Holanda?' En esa desmesura apunta Saer-, mi amigo veía ya una dificultad, como si yo debiese, no escribir sobre el estuario, sino atravesarlo a nado"'

7 T. S. Eliot parece hablar en nombre de todos los poetas, o de la poesía misma, cuando, al principio del tercero de los Cuatro cuartetos, en "The Dry Salvages" (1941), y acaso evocando el mismo pasaje de Virgilio que hemos citado, escribía:
I do not know much about gods; but I think that the river
Is a strong Brown god -sullen, untamed and intractable,
Patient to some degree, at first recognised as a frontier
Useful, untrustworthy, as a conveyor of commerce;
The only a problem confronting the builder of bridges.
No es que yo sepa mucho sobre dioses, pero me parece que el río
es un dios pardo y fuerte, hosco, indómito y huraño,
paciente hasta cierto punto, reconocido al principio como límite,
útil e inseguro como ruta de comercio;
luego sólo un problema para el constructor de puentes ${ }^{8}$.

El pasaje es una visión del río Misisipi desde Sant Louis, Missouri, ciudad natal de Eliot, donde vivió hasta los dieciocho años. En 1906 fue a estudiar a Harvard y a partir de 1914 vivió en Inglaterra. En 1932 visitó Estados Unidos después de muchos años; fue seguramente entonces cuando tuvo la idea de titular los primeros tres de los Cuatro cuartetos con nombres de lugares vinculados a su juventud y a su familia. "The Dry Salvages" (el nombre parece una deformación de "Les trois sauvages", como aclara Eliot) son unas rocas con una baliza en Cape Ann, en la costa atlántica de Massachusetts, donde el poeta veraneaba en su infancia. En el poema, el río ha dejado de ser materialización del tiempo, de la fluida eternidad. Ahora es uno de los dioses; no sabemos cuáles son los otros; seguramente cada uno de los grandes ríos del mundo tiene el suyo, como en la fuente de los cuatro ríos de Bernini, en la Piazza Navona de Roma, constituida de cuatro alegorías: el Nilo, el Ganges, el Danubio y el Río de la Plata. Interesa, en todo caso, el hecho de que el Misisipi es un dios algo más corpóreo que los otros símbolos con los que nos encontramos hasta ahora: es "pardo y fuerte, hosco, indómito y huraño,/ paciente hasta cierto punto, reconocido al principio como límite...". Eliot huye aquí del tópico europeo en la asimilación del río a una ciudad, como vimos en Quevedo y Góngora, y también en Auden. En el paisaje americano, en los grandes ríos de llanura del continente, la ciudad no ha domesticado al río, no lo ha canalizado ni lo controla, no puede instalarse a ambas márgenes unidas por puentes; el poema dice explícitamente que para "el constructor de puentes" el río es "un problema". El río ya no puede atravesar la ciudad; es su límite. La ciudad está a la orilla del río, una orilla que no siempre deja ver la ribera opuesta. En el mismo poema, unos versos más abajo, leemos:

The river is within us, the sea is all about us 
El río lo llevamos dentro, el mar nos rodea por entero.

Si el río en cuestión hubiera sido el Río de la Plata quizás tendría que haber escrito que lo llevamos dentro y, a la vez, nos rodea por entero; es decir, que habitamos simultáneamente en el tiempo y en la eternidad, o en la cronología y en lo intemporal. Por eso ese río -ese estuario- es tan difícil de mirar, de abarcar con la mirada. Volvamos al principio de El río sin orillas: al día siguiente de llegar a Buenos Aires, a comienzos de diciembre de 1989, Juan José Saer, ansioso por empezar a trabajar en su encargo, toma un taxi en dirección a Aeroparque y se baja justo enfrente del aeropuerto, en una "saliente reducida, una especie de balcón que se interna un poco en el agua, [donde] consideré que se me ofrecía un buen punto de observación". ${ }^{9}$ Allí, anota, "tenía la esperanza de que, en algún punto despejado entre el agua y el cielo, se pusieran a flotar las imágenes necesarias". Pero, aunque se queda un buen rato esperando, la visión no tiene lugar, nada sucede. Lo que el autor denomina "el prestigio legendario de la experiencia" no cunde esta vez. Por fin, abandona su intento, y concluye: "La experiencia directa no había funcionado: tenía que resignarme a la erudición"10. Para escribir su propio informe tendrá que recurrir a otros, a los libros de historia, de geografía, de economía, etc. Como en Eliot, aunque expresado de modo distinto, irrumpe la certeza de que del río no se puede saber nada directamente; es inasible a los sentidos, solo se lo puede abordar desde las bibliotecas.

10 "I do not know much about gods", escribe Eliot en 1941. Veinte años más tarde, hacia 1961, según la datación de Sergio Delgado, Juan L. Ortiz escribe “Al Paraná”, poema de 182 versos que aparecerá en El junco y la corriente, libro que no se publica como volumen aparte sino que se incorpora a la edición de 1970 de En el aura del sauce. El poema de Ortiz empieza de este modo:

Yo no sé nada de ti.

Yo no sé nada de los dioses o del dios de que naciste

ni de los anhelos que repitieras

antes, aún de los Añax y los Tupac hasta la misma

azucena de la armonía

nevándote, otoñalmente, la despedida

a la arenilla... ${ }^{11}$

11 El "no sé nada de ti" se repite una decena de veces a lo largo del poema ${ }^{12}$. Por otra parte, sorprende la mención aquí de dos deidades, Añax y Tupac, ajenas a la mitología guaraní asimilada al paisaje que Juan L. pone en juego profusamente en varios de sus poemas mayores, como El Gualeguay. ¿Alude Añax al gigante Anax, hijo de los dioses Urano y Gea? ¿La mención de Tupac quiere ligar el "dios de que naciste", ese Paraná "padre de ríos", con un panteón panamericano? Ahora es el lector el que se encuentra en situación de no saber, porque estas referencias ajenas al paisaje del Paraná resultan opacas y enigmáticas. Eliot se reencuentra con el Misisipi, su paisaje de origen, después de años de ausencia; en tanto que Ortiz está frente al Paraná desde 1942, cuando, a sus 46 años y tras jubilarse por anticipado de su trabajo en el registro civil de Gualeguay, se instala en la capital de la provincia de Entre Ríos, en una casa con vista al río. Sin embargo, es significativo que el poema "Al Paraná" se encuentre en un conjunto que, como sucede con El junco y la corriente, está presidido por los poemas que Ortiz escribió durante su viaje a China, en 1957, única vez en su vida que abandonó Argentina. Esos poemas, dominados por la visión del gran río asiático, el Yang-Tsé, señalan un punto máximo de extrañamiento con el paisaje, que sin embargo no se resuelve en familiaridad con el Paraná, al regreso. La sensación de no saber es, allí, más angustiosa, puesto que se trata, precisamente, del lugar donde se está, del lugar propio. 

del Paraná, ni "de los dioses o del dios de que naciste". Francisco Bitar lleva más allá la relación entre ambos poemas: "El paralelismo entre río y mar en el poema de Eliot [...] es recuperado por Ortiz desde el momento en que la voz guaraní para rehe onáva, de la que Paraná es el apócope, significa 'pariente del mar' o 'agua que se mezcla con el mar' "13. La primera traducción de los Four Quartets al castellano la hizo Vicente Gaos y se publicó en 1951 en Madrid, en ediciones Rialp; la segunda, de Juan Rodolfo Wilcock, se publicó en Buenos Aires en 1956 (en la editorial Raigal). ¿Habrá llegado esta última a manos de Juan L. Ortiz? ¿Se había quedado en su memoria esa música acerca del no saber nada o el no saber mucho sobre el río o sobre el dios del que nace el río? Es cierto que ya en 1934, en una conferencia en "la Peña de Vértice", el primero de sus escritos sobre poética entre los reunidos bajo el título de "Comentarios", en este caso sobre lo inefable del arte y de la poesía, Ortiz menciona a Eliot $^{14}$; pero es un nombre más entre las numerosas referencias que aporta: Valéry, Pound, Joyce, J. R. Jiménez, Bergson, Ungaretti... Y no el más importante: las citas más extensas son de un poema de Pedro Salinas y de un ensayo de Antonio Marichalar, Mentira desnuda, que se había publicado en Madrid el año anterior, 1933. De esta cita de Marichalar, por otra parte, Daniel García Helder extrajo el título de su prefacio a la poesía completa de Ortiz, "Un léxico, un sistema, una clave". Por otra parte, Antonio Marichalar había sido, en 1923, el primer colaborador español de The Criterion, la revista que T. S. Eliot acababa de lanzar en Londres. Eliot le había encargado un artículo panorámico de la poesía española de entonces, que Marichalar centró en Juan Ramón Jiménez, a quien Ortiz leyó con gran interés.

En el libro de Saer paralelo y especular respecto de El río sin orillas, El entenado, el río tiene "olor a origen", la vida es "primigenia" y las orillas son "primordiales". El Paraná no es "pariente del mar" sino "padre de ríos"15. Esa "horda de hombres desnudos, de piel oscura", los primeros que ve el grumete en el mismo momento en que sus compañeros de expedición son atravesados por precisas flechas en el cuello y en el pecho, parecen encarnar la intuición de Michel de Montaigne, quien, en su ensayo "De los caníbales", había creído ver en los indígenas americanos a "Viri a diis recentes": hombres recién hechos por los dioses ${ }^{16}$. El hombre que, en la visión del entenado, tiene la piel del mismo color que el agua del río, es, a la vez, un hijo reciente de los dioses, como el río americano para Eliot y para Ortiz: es el doble sueño del hombre adánico y edénico, anterior a su corrupción y caída; y de América como segunda oportunidad para la historia de Occidente. Esa "esencia pastosa" de que están hechos los individuos de la tribu es algo acerca de lo cual tampoco hay saber, solo hay fenómeno: "No sé qué dios podía ser, si era un dios, aunque nunca vi en tantos años que esos indios adoraran nada; era una presencia que los gobernaba a pesar de ellos". También aquí, el río y el dios están unidos al no saber.

El "no saber" es clave en la actitud de Juan L. (y, en esa perspectiva, también de Saer) respecto del paisaje y del poema: el poeta que quiere conocer y captar algo de lo que mira debe despojarse, antes, de todo conocimiento adquirido. En este aspecto, Ortiz adhiere a una corriente que tiene su raíz en el simbolismo, particularmente en Mallarmé, a quien Ortiz evoca varias veces en los poemas "chinos" de El junco y la corriente; por ejemplo, en "Luna de Pekín": "en lo hondo, dicen,/ la eternidad lo igualara?"17, evidente alusión al soneto "Le tombeau d'Edgar Poe". "Tel que lui même en fin l'éternité le change...". Me refiero a la sospecha acerca de la concordancia entre nombre y objeto, entre palabra y mundo. Es la corriente que, convertida en extrañamiento, en desautomatización de la percepción, recorre el siglo XX, y que Ortiz hizo suya de un modo particular. Para percibir 
el mundo hay que extrañarlo, hay que desconocerlo; para captar algo esencial de su objeto el poeta tiene, antes, que desaprenderlo y desprenderse de él. En su peculiar objetivismo espiritualizado, Ortiz no está lejos de otros poetas que, para escribir, necesitan no saber nada acerca de lo que miran; por ejemplo, el Francis Ponge de Le Parti pris des choses (1942): "On pourrait presque dire que l'eau es folle, à cause de cet hystéryque besoin de n'obéir qu'à sa pesanteur, qui la possède como une idée fixe" ${ }^{18}$. Ni siquiera del agua se puede afirmar algo, apenas se puede presque dire...

En 1989, Saer escribe un prólogo para una antología de Ortiz, que luego recogerá, bajo el adusto título de "Juan", en El concepto de ficción. El artículo empieza citando a Eliot: "Los libros para los que escribiríamos de buena gana un prólogo son precisamente aquellos que no lo necesitan"19. Aquellos para los que todo saber resulta superfluo. Y más adelante: "Para la poesía de Juan el paisaje es enigma y belleza, pretexto para preguntas y no para exclamaciones, fragmentos del cosmos por el que la palabra avanza sutil y delicada, adivinando en cada rastro o vestigio, aun en los más diminutos, la gracia misteriosa de la materia". El paisaje, la materia: el río, del que no se sabe nada y sin embargo debe ser dicho.

\section{NOTAS}

1. W. H. Auden, Otro tiempo, trad. de Álvaro García, Valencia, Pre-textos, 1993.

2. Juan Gelman, “Nota XXIV”, Poesía reunida, vol. 1, Buenos Aires, Seix Barral, 2012, p. 399.

3. Geneviève Fabry, Las formas del vacío. La escritura del duelo en la poesía de Juan Gelman, Amsterdam-New York, Editions Rodolpi B.V., 2008, p. 165.

4. Jorge Luis Borges, Poesía completa, Barcelona, Lumen, 2011, p. 150.

5. Francis Ponge, La soñadora materia, ed. de Miguel Casado, Barcelona, Galaxia Gutenberg/Círculo de Lectores, 2006, p. 88.

6. José Gorostiza, Poesía, México, FCE, 1971, p. 107.

7. Juan José Saer, El río sin orillas, Buenos Aires, Alianza, 1994, p. 23-24.

8. T. S. Eliot, Cuatro cuartetos, ed. y trad. de Andreu Jaume, Barcelona, Lumen, 2016, p. 109.

9. Juan José Saer, El río sin orillas, op. cit., p. 32.

10. Ibidem, p. 33.

11. Juan L. Ortiz, Obra completa, ed. de Sergio Delgado, Santa Fe, Universidad Nacional del Litoral, 1996, p. 598.

12. La proximidad entre el inicio del poema de Ortiz y el de Eliot fue notada por Daniel García Helder en una nota al pie de su ensayo introductorio a En el aura del sauce: "se oye un eco, no del todo manifiesto pero tampoco disimulado, del comienzo de 'Las Dry Salvages' (sic) de Eliot” (“Juan L. Ortiz: un léxico, un sistema, una clave”, Juan L. Ortiz, Obra completa, op. cit., p. 131).

13. Francisco Bitar, Juan L. Ortiz, El junco y la corriente, ed., introducción y notas de Francisco Bitar, Paraná-Santa Fe, EDUNER, colección “El país del sauce”, 2013, p. 200.

14. Juan L. Ortiz, Obra completa, op. cit., p. 1050.

15. Juan José Saer, El entenado, Barcelona, El Aleph, 2003, p. 36.

16. Michel de Montaigne, Los ensayos (según la edición de 1595 de Marie de Gournay), ed. y trad. de J. Bayod Brau, Barcelona, Acantilado, 2007, p. 281. 
17. Juan L. Ortiz, El junco y la corriente, op. cit., p. 5.

18. Francis Ponge, op. cit., p. 88

19. Juan José Saer, El concepto de ficción, Buenos Aires, Ariel, 1997, p. 82.

\section{RESÚMENES}

La tradición poética elabora complejas resonancias sobre la identificación entre río y tiempo; el río divide en dos a la ciudad que atraviesa, y a la propia ciudad de su arquetipo glorioso y arcaico. En la ciudad americana, en cambio, el río es un margen o límite. En algunos escritores y poetas americanos -T.S. Eliot, Juan L. Ortiz, Juan José Saer- se proclama el "no saber" acerca del río como posibilidad o necesidad de su plasmación en el poema.

La traduction poétique construit des résonances complexes sur l'identification entre le fleuve et le temps. Le fleuve traverse la ville. Celle-ci est divisée en deux parties par le fleuve. La ville est même divisée de son glorieux et archaïque archétype. Dans la ville américaine, en revanche, le fleuve est une marge ou une limite. Certains écrivains et poètes américains -T.S. Eliot, Juan L. Ortiz, Juan José Saer- proclament le «non-savoir » comme possibilité ou nécessité de façonner le fleuve dans le poème.

Poetic tradition produces complex echos regarding the representation of time as a river's flow. A river divides the city it runs through in two, and also the city itself, from its glorious and archaic archetype. In american cities, however, the river itself is a margin or a limit. Some American writers and poets - T.S.Eliot, Juan L. Ortiz, Juan José Saer - proclaim "not knowing" about the river as a possibility or as a necessity for shaping it in poetry.

\section{ÍNDICE}

Palabras claves: Quevedo, Góngora, Auden, Eliot, Juan L. Ortiz, Juan José Saer, tiempo, ciudad, no saber.

Keywords: Quevedo, Góngora, Auden, Eliot, Juan L. Ortiz, Juan José Saer, time, city, not knowing. Mots-clés: Quevedo, Góngora, Auden, Eliot, Juan L. Ortiz, Juan José Saer, temps, ville, non-savoir.

\section{AUTOR}

\section{EDGARDO DOBRY}

Universidad de Barcelona

edgardo.dobry@gmail.com 